\title{
Reversal of Established Rat Crescentic Glomerulonephritis by Blockade of Macrophage Migration Inhibitory Factor (MIF): Potential Role of MIF in Regulating Glucocorticoid Production
}

\author{
Niansheng Yang, ${ }^{1}$ David J. Nikolic-Paterson, ${ }^{2}$ Yee-Yung Ng, ${ }^{4}$ \\ Wei Mu, ${ }^{2}$ Christine Metz, ${ }^{5}$ Michael Bacher, ${ }^{5}$ Andreas Meinhardt, ${ }^{3}$ \\ Richard Bucala, ${ }^{5}$ Robert C. Atkins, ${ }^{2}$ and Hui Y. Lan ${ }^{2}$ \\ ${ }^{1}$ The First Hospital, Sun Yat-Sen University of Medical Sciences, \\ Ghongzhou, China \\ ${ }^{2}$ Department of Nephrology and the ${ }^{3}$ Institute for Reproduction and \\ Development, Monash Medical Centre, Clayton, Victoria, Australia \\ ${ }^{4}$ Department of Nephrology, Veterans General Hospital-Taipei, \\ National Yang-Ming University, Taipei, Taiwan \\ ${ }^{5}$ Picower Institute for Medical Research, Manhasset, New York, U.S.A. \\ Communicated by R. Bucala. Accepted April 28, 1998.
}

\begin{abstract}
Macrophage migration inhibitory factor (MIF) is a potent pro-inflammatory cytokine that also counter-regulates glucocorticoid action. We investigated whether immunoneutralization of MIF could reverse established experimental crescentic glomerulonephritis and if this treatment could modulate endogenous glucocorticoid levels. Accelerated anti-GBM glomerulonephritis was induced in six littermate pairs of rats. Once crescentic disease was established on day 7, one animal in each pair was given a daily injection of neutralizing anti-MIF antibody (Ab) or irrelevant isotype control $\mathrm{Ab}$ for 14 days and then killed on day 21 . In addition, a group of 6 animals was killed on day 7 of disease without any treatment. Animals receiving the control $\mathrm{Ab}$ exhibited a rapidly progressive glomerulonephritis with severe renal injury (proteinuria), loss of renal function (creatinine clearance), anemia, and marked histologic damage (including glomerular crescent formation), compared with animals
\end{abstract}

killed on day 7 without treatment. In contrast, anti-MIF $\mathrm{Ab}$ treatment partially reversed the disease by restoring normal renal function and reducing histological damage compared with untreated animals killed on day 7 ( $p<$ $0.05)$. Interestingly, anti-MIF Ab treatment also prevented severe anemia $(p<0.05)$. Reversal of disease was associated with a significant reduction in leukocyte infiltration and activation and renal interleukin-1 (IL-1) production. Importantly, anti-MIF Ab treatment caused a significant increase in endogenous serum corticosterone levels, which correlated with the reversal of disease parameters. In conclusion, this study has demonstrated that blocking MIF activity can partially reverse established crescentic glomerulonephritis and suggests that MIF operates by both enhancing the cellular immune response and suppressing the endogenous anti-inflammatory glucocorticoid response.

\section{Introduction}

Macrophage migration inhibitory factor (MIF) was first described over 30 years ago as a product

Address correspondence and reprint requests to: Hui Y. Lan, Ph.D., Department of Nephrology, Monash Medical Centre, 246 Clayton Road, Clayton, Victoria 3168, Australia. Phone: 61-3-9550 3534; Fax: 61-3-9550 3530; E-mail: huilan@its-mmccl.cc.monash.edu.au of activated $\mathrm{T}$ cells that inhibited the migration of macrophages in vitro and promoted macrophage accumulation in the skin delayed-type hypersensitivity reaction $(1,2)$. The recent cloning and characterization of MIF has led to the recognition that this molecule occupies a pivotal position in regulating the inflammatory and immune responses (3). The use of neutralizing antibodies (Ab) has confirmed the central role of MIF in the 
cutaneous response to tuberculin (4). In addition, a requirement for MIF in primary $\mathrm{T}$ cell activation and $\mathrm{T}$ cell-dependent immunoglobulin production has been demonstrated in vitro and in vivo (5). An unexpected property of MIF was the discovery that it acts as a counterregulator for glucocorticoid action. Injection of dexamethasone into mice causes an increase in serum MIF levels, while the addition of recombinant MIF overcomes dexamethasone-mediated inhibition of lipopolysaccharide-induced cytokine secretion in vitro (6). In addition, administration of recombinant MIF can overcome dexamethasone inhibition of lethal endotoxemia in mice (6). Consistent with its role as a regulator of glucocorticoids, preformed MIF is present at high levels within secretory granules of corticotrophic cells of the anterior pituitary (7). Indeed, MIF is widely expressed in most normal tissues $(8,9)$.

We have recently described constitutive MIF expression by intrinsic glomerular and tubular epithelial cells of the rat kidney. There is a marked increase in both renal and systemic MIF production during the development of crescentic glomerulonephritis in the rat, which is dependent upon tumor necrosis factor- $\alpha$ (TNF- $\alpha$ ) activity $(10,11)$. Treatment of rats with a neutralizing anti-MIF antibody (Ab) significantly inhibits the induction of this aggressive model of kidney disease, providing the first evidence that MIF participates in the pathogenesis of immunologically induced disease (12). This inhibition of disease induction was associated with a suppression of blood monocyte recruitment and subsequent macrophage-mediated tissue injury. This finding has opened up two important questions. First, can anti-MIF Ab treatment reverse established crescentic glomerulonephritis? This is the situation encountered in clinical practice and the setting in which any new therapy must be effective. Second, does immunoneutralization of MIF affect circulating glucocorticoid levels? This may be an important component of the pro-inflammatory actions of MIF in immunemediated disease. These two questions have been addressed in a study in which established crescentic glomerulonephritis in rats was treated with a neutralizing anti-MIF or irrelevant isotype control antibody and the effect upon disease progression/resolution and serum glucocorticoid levels examined.

\section{Materials and Methods}

\section{Antibodies and Probes}

The following mouse antibodies $(\mathrm{Ab})$ were used: IIID9, a mouse anti-murine MIF monoclonal Ab raised to purified recombinant mouse MIF, which neutralizes the bioactivity of mouse, rat, and human MIF (13); OX-1; anti-rat CD45, a leukocyte common antigen (14); EDl, an antirat CD68 that labels most monocytes and macrophages $(15,16)$; $\mathrm{R} 73$, which recognizes a nonpolymorphic epitope of the $\alpha \beta$ T cell receptor (17); NDS 61, an anti-rat CD25, p55 chain of the rat interleukin-2 receptor (IL-2R) (18); MCA 1397, an anti-rat recombinant IL- $1 \beta$ (Serotec, Oxford, UK) (19); and 73.5, a mouse anti-human CD45R mAb that does not react with rat tissues; this was used as a negative control. Peroxidase-conjugated goat anti-mouse IgG and mouse peroxidase anti-peroxidase complexes were purchased from Dakopatts (Glostrup, Denmark). Fluorescein isothiocyanate (FITC)-conjugated goat anti-rat IgG, anti-rat $\mathrm{C} 3$, and FITCconjugated sheep anti-rabbit IgG were purchased from Nordic (Tilburg, The Netherlands).

A 420 bp fragment of mouse MIF cDNA cloned into pBluescript (Stratagene, La Jolla, CA) (20), was used to prepare digoxigenin (DIG)labeled cRNA sense and anti-sense probes for in situ hybridization according to the manufacturer's protocol (Boehringer Mannheim, Mannheim, Germany).

\section{Experimental Design}

Passive accelerated anti-GBM disease was induced in inbred male Sprague-Dawley rats (150$180 \mathrm{~g}$ ) (Monash Animal Services, Melbourne) as previously described (21). Each experiment consisted of a matched pair of inbred littermates immunized at the same time by s.c. injection of 5 mg normal rabbit IgG in Freund's complete adjuvant, followed 5 days later (day 0 ) by i.v. injection of $10 \mathrm{ml} / \mathrm{kg}$ body weight rabbit anti-rat glomerular basement membrane (GBM) serum (12.5 $\mathrm{mg} \mathrm{IgG/ml}$ ). One animal in each pair was randomly assigned to treatment with daily i.p. injections of $2.5 \mathrm{mg} / \mathrm{kg}$ anti-MIF Ab or an irrelevant isotype IgGl (73.5) control Ab from day 7 until being killed on day 21 . A third group was killed on day 7 after injection of anti-GBM serum with no treatment in order to serve as a control for the degree of renal injury at the time antibody treatment commenced. Blood and 24-hr urine collections were taken on days $0,1,7,14$, 
and 21. A group of normal rats was also examined. Animal experiments were approved by the Animal Experimentation Ethics Committee of Monash Medical Centre. Urinary protein excretion was determined using the Manual Ponceau Red method. Concentrations of serum and urine creatinine, and serum urea were determined using the standard Jaffe rate reaction (alkaline picrate) or NED/OPA assay, respectively. Heparinized blood samples were taken under ether anesthesia at the time of sacrifice and white blood cells were analyzed by Coulter Counter (Cell Dyne). All analyses were performed by the Departments of Biochemistry and Haematology, Monash Medical Centre.

\section{Skin Delayed-Type Hypersensitivity Response}

Twenty-four hours prior to being killed, each animal was given three separate intradermal injections of $0.1 \mathrm{ml}$ each of $1 \mathrm{mg} / \mathrm{ml}$ rabbit $\mathrm{IgG}$ (specific antigen challenge), $1 \mathrm{mg} / \mathrm{ml}$ horse IgG (irrelevant antigen control), and phosphate buffered saline (PBS) (no antigen control). Skin thickness at the time of killing was measured using engineer's callipers.

\section{Histopathology}

Tissues were fixed in $4 \%$ buffered formalin and 4- $\mu \mathrm{m}$ paraffin sections were stained with hematoxylin and eosin (HEE) or periodic acid-Schiff (PAS) reagent. Glomerular hypercellularity was graded on the basis of the total glomerular cell count/glomerular cross section (gcs) scored in 100 glomerular cross sections per animal in HEE-stained sections and ranked as previously described (22): (0), normal (<50 cells/gcs); (1), mild (60-80 cells/gcs); (2), moderate (80-120 cells/gcs); (3), severe hypercellularity (>120 cells/gcs). The percentage of glomeruli exhibiting segmental and/or global sclerosis or crescent formation was also scored in 100 glomeruli per animal in PAS-stained sections. A point counting technique was used to quantitate tubulointerstitial damage (tubular atrophy, leukocytic infiltration, and fibrosis) in at least 50 high-power cortical fields in PAS-stained sections (23). Data are presented as the mean of 6 animals \pm SEM. Scoring was performed on blinded slides.

\section{Measurement of the Humoral Immune Response}

Circulating levels of rat IgG reactive with rabbit immunoglobulin were quantitated by a sand- wich ELISA, as previously described (24). Deposition of immune reactants within the kidney was assessed by direct immunofluorescence. Tissues were snap frozen in liquid nitrogen and $4-\mu \mathrm{m}$ cryostat sections were stained with FITCconjugated polyclonal antibodies to rat IgG, C3, or rabbit IgG. Semi-quantitation of rabbit IgG, rat IgG, and C3 deposition was determined in tissue sections using an antibody titration method $(22,24)$. Sections from each tissue were incubated with serial 2 -fold dilutions of each antibody. Slides were blinded and the antibody dilution at which staining became undetectable was scored.

\section{Immunohistochemistry}

Three-layer immunoperoxidase staining was performed on cryostat sections of tissues fixed in $2 \%$ paraformaldehyde-lysine-periodate (PLP) as previously described (22). Briefly, sections were preincubated with $10 \%$ fetal calf serum (FCS) and $10 \%$ normal goat serum in PBS for $20 \mathrm{~min}$, drained, and labeled with a mouse mAb for 60 min, washed $(\times 3)$ in PBS, and endogenous peroxidase inactivated by incubation in $0.3 \% \mathrm{H}_{2} \mathrm{O}_{2}$ in methanol. Sections were then washed in PBS, incubated with peroxidase-conjugated goat antimouse IgG, washed in PBS, and incubated with mouse peroxidase anti-peroxidase complexes and developed with 3,3-diaminobenzidine to produce a brown color. Sections were counterstained with PAS minus hematoxylin.

\section{In Situ Hybridization}

In situ hybridization was performed on $4-\mu \mathrm{m}$ paraffin sections of formalin-fixed tissue using a microwave-based protocol $(10,25)$. After dewaxing, sections were treated with $2 \times 5$ min microwave oven heating in $0.01 \mathrm{M}$ sodium citrate, $\mathrm{pH}$ 6.0 , at $2450 \mathrm{MHz}$ and $800 \mathrm{~W}$, incubated with 0.2 $\mathrm{M} \mathrm{HCl}$ for $15 \mathrm{~min}$, followed by $1 \%$ Triton X-100 for $15 \mathrm{~min}$, and then digested for 20 min with 10 $\mu \mathrm{g} / \mathrm{ml}$ proteinase- $\mathrm{K}$ at $37^{\circ} \mathrm{C}$ (Boehringer Mannheim). Sections were then washed in $2 \times$ SSC, prehybridized, and then hybridized with 0.3 $\mathrm{ng} / \mu \mathrm{l}$ digoxigenin-labeled sense or anti-sense MIF cRNA probe overnight at $42^{\circ} \mathrm{C}$ in a hybridization buffer containing $50 \%$ deionized formamide, $4 \times$ SSC, $1 \mathrm{mg} / \mathrm{ml}$ salmon sperm DNA, and $1 \mathrm{mg} / \mathrm{ml}$ yeast tRNA. Sections were washed finally in $0.1 \times \mathrm{SSC}$ at $42^{\circ} \mathrm{C}$ and the hybridized probe detected using alkaline phosphatase-conjugated sheep anti-digoxigenin $F(a b)$ fragments 
and color development with NBT/X-phosphate. Sections were counterstained with PAS minus hematoxylin. Hybridization with the MIF cRNA sense probe gave no signal.

\section{Quantitation of Tissue Staining}

A standard semi-quantitative method was used to score the glomerular and tubulointerstitial infiltrates as previously described $(10,22,24)$. Cells labeled by each mAb or by the MIF cRNA probe were counted in high-power fields $(\times 40)$ of 20 consecutive glomerular cross sections for each animal and expressed as the number of labeled cells per glomerular cross section (gcs). Glomerular staining with the anti-IL- $1 \beta$ Ab was graded on a scale of $(0)$ no staining; $(1)<25 \%$ stained; (2) $25-50 \%$ stained; (3) $>50 \%$ of the gcs stained. To assess interstitial staining, cortical areas were selected at random. The number of labeled interstitial cells was counted in 20 consecutive high-power fields by means of a 0.02 $\mathrm{mm}^{2}$ graticule fitted in the eyepiece of the microscope and expressed as cells per $\mathrm{mm}^{2}$. These fields progressed from the outer to inner cortex, avoiding only large vessels and glomerular and immediate periglomerular areas. For each tissue, the same area was examined in serial sections labeled with different Ab. No adjustment of the interstitial cell count was made for tubules or the luminal space. Tubular expression of MIF and IL- $1 \beta$ was scored in at least 1000 cortical tubules in high-power fields as previously described (12). Data are expressed as the mean for six animals \pm SEM. All counting was performed on blinded slides.

\section{Glomerular MIF Production}

Glomeruli were isolated by differential sieving in which a half kidney from each animal was placed in RPMI 1640 medium with 5\% FCS, diced finely, gently pressed through a $250-\mu \mathrm{m}$ wire mesh and poured through a 106- $\mu \mathrm{m}$ and then a $75-\mu \mathrm{m}$ wire mesh. Glomeruli remaining on the top of the $75-\mu \mathrm{m}$ mesh were washed extensively with RPMI/5\% FCS and collected. Isolated glomeruli were $>95 \%$ pure as assessed by phasecontrast microscopy. Glomeruli were cultured at 3000 glomeruli $/ \mathrm{ml}$ in RPMI $1640 / 5 \%$ FCS in $5 \%$ $\mathrm{CO}_{2}$ at $37^{\circ} \mathrm{C}$ for $24 \mathrm{hr}$ and the supernatant harvested. The concentration of MIF in the supernatant samples was quantitated by a sandwich ELISA (6).

\section{Corticosterone Assay}

Animals were bled under ether anesthesia between 9 and 10 a.m. and serum samples prepared. Serum corticosterone levels were measured by radioimmunoassay using an antiserum prepared by immunizing rabbits with 4-pregnen11 $\beta, 21$-diol-3,20-dione 3-CMO: BSA conjugate (Steraloids Inc., Wilton, $\mathrm{NH}$ ). A known amount of unlabeled corticosterone, or the test serum sample, was adjusted to a $0.2 \mathrm{ml}$ volume in gelatin buffer $(0.1 \%$ gelatin in PBS, $\mathrm{pH} 7.5)$ and incubated with $0.1 \mathrm{ml}(\sim 8000 \mathrm{cpm})$ of $[1,2,6,7-$ $\left.{ }^{3} \mathrm{H}\right]$ corticosterone (TRK 406, Amersham International, Buckinghamshire, UK) and $0.1 \mathrm{ml}$ of a $1: 16,000$ dilution of corticosterone antiserum, both in gelatin buffer. After overnight incubation at $4^{\circ} \mathrm{C}, 0.2 \mathrm{ml}$ of $0.25 \%$ dextran-coated charcoal was added, incubated for $15 \mathrm{~min}$ in an ice bath, and tubes centrifuged at $1000 \times g$ for $15 \mathrm{~min}$. The supernatant was removed and mixed with 3 $\mathrm{ml}$ of liquid scintillation fluid (Ready Safe, Beckman, CA) and radioactivity counted on a Wallace 1409 automated $\beta$-counter (Pharmacia, Stockholm, Sweden). Duplicate samples covering a range of 2.5 to $1200 \mathrm{pg}$ of corticosterone were assayed to form the standard curve. The level of detection of the assay was $5 \mathrm{pg}$ corticosterone per tube. Inhibition curves produced by extracted rat serum were parallel to that of unlabeled corticosterone. The intra-assay and interassay coefficients of variation were $3.3 \%$ and $9.2 \%$, respectively.

\section{Statistical Analysis}

Data were analyzed by one-way analysis of variance (ANOVA) using the Complete Statistical Systems program (Statsoft, Tulsa, OK).

\section{Results}

\section{Renal Function and Histological Damage}

All animals on day 7 of anti-GBM disease exhibited significant proteinuria $(p<0.001$ vs. normal), a significant increase in serum creatinine levels ( $p<0.01$ versus normal), and a decrease in creatinine clearance (not significant) (Fig. 1). Animals killed on day 7 of disease with no treatment exhibited significant glomerular and tubular lesions, including glomerular crescent formation (Fig. 2). There was rapid progression of crescentic glomerulonephritis in those animals treated with the irrelevant control Ab over days 7 to 21 , with ascites evident in 3 of 6 animals. 
(a) Proteinuria

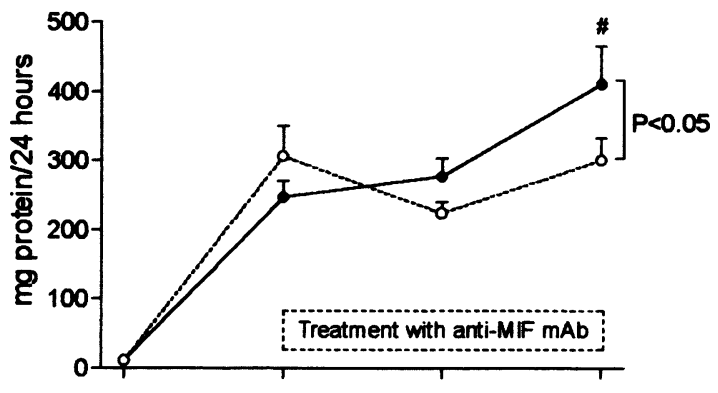

(b) Serum Urea

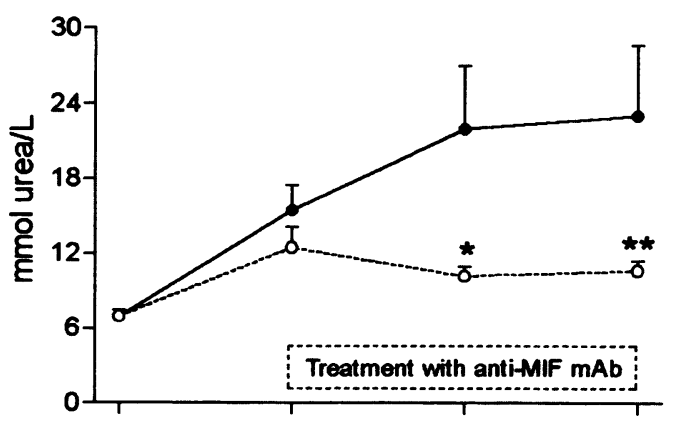

(c) Serum creatinine

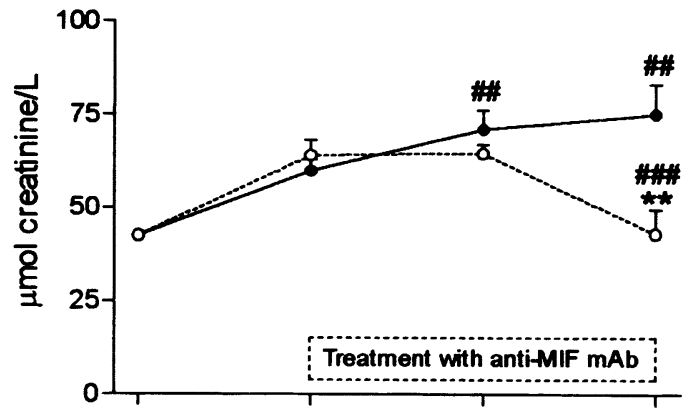

(d) Creatinine clearance

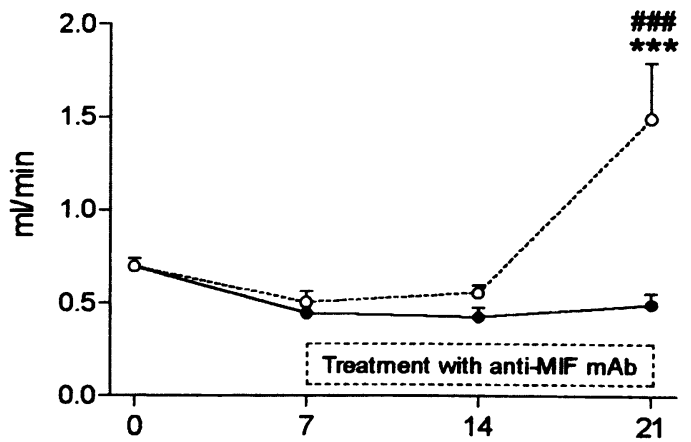

Days after induction of disease
Fig. 1. Anti-MIF Ab treatment improves renal function in rat anti-GBM disease. The effect of anti-MIF Ab (open circles, dotted line) and irrelevant control Ab treatment (closed circles, solid line) was assessed in terms of (a) urinary protein excretion, (b) serum urea levels, (c) serum creatinine levels, and (d) the rate of creatinine clearance. Data are shown as the mean \pm SEM for six animals. ${ }^{\star} p<$ $0.05,{ }^{* *} p<0.01,{ }^{* *} p<0.001$ versus time-matched control Ab-treated animals; ${ }^{*} p<0.05,{ }^{\# \#} p<0.01$, $\# \# p<0.001$ versus day 7 by ANOVA. The group of six animals killed on day 7 of disease without any treatment had $291 \pm 42 \mathrm{mg}$ protein $/ 24 \mathrm{hr}, 17.3 \pm$ $3.5 \mathrm{nmol}$ urea/L, $63 \pm 6.8 \mu \mathrm{mol}$ creatinine $/ \mathrm{L}$, and $0.48 \pm 0.03 \mathrm{ml} / \mathrm{min}$ creatinine clearance.

This is consistent with previous studies in which animals treated with saline or an irrelevant control antibody developed a very similar, rapid progressive disease $(8,12,26)$. In contrast, those animals treated with the anti-MIF Ab showed a partial reversal of established crescentic glomerulonephritis. In particular, serum levels of urea and creatinine returned to the normal range and animals exhibited hyperfiltration (increased creatinine clearance) (Fig. 1). Furthermore, there was a significant reduction in glomerular hypercellularity, segmental lesions, and crescent formation in animals treatment with anti-MIF Ab compared with animals killed on day 7 without any treatment (Fig. 2).

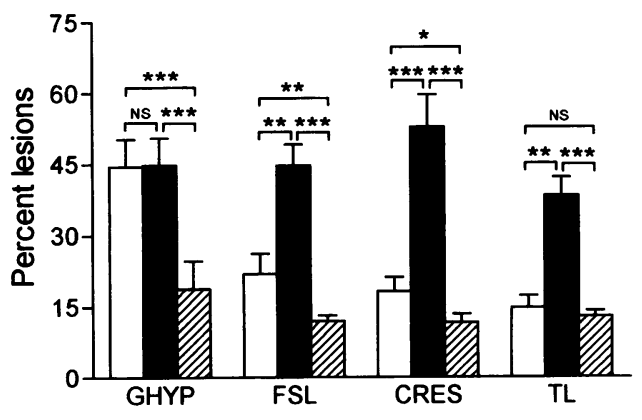

Fig. 2. Anti-MIF Ab treatment partially reverses renal histological damage in rat antiGBM disease. The percent of glomeruli exhibiting hypercellularity (GHYP), focal and segmental lesions (FSL), and crescents (CRES) and the percent cortical interstitial lesions (TL) were scored in animals killed on day 7 of disease without any treatment (open bars), and after treatment with an irrelevant control $\mathrm{Ab}$ (closed bars) or an anti-MIF Ab (hatched bars) over days 7 to 21 . Note that none of these glomerular or interstitial lesions are seen in normal animals. Data are shown as the mean \pm SEM for six animals. ${ }^{*} p<0.05,{ }^{* *} p<0.01,{ }^{* * *} p<0.001$, and not significant (NS), by ANOVA. 


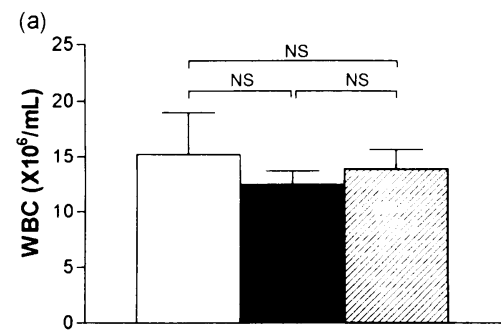

(b)
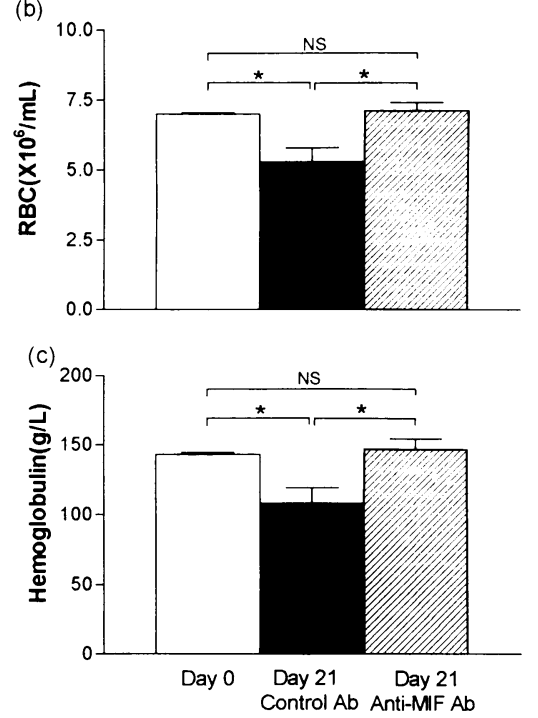

Fig. 3. Anti-MIF Ab treatment prevents anemia in rat anti-GBM disease. White blood cell counts (a), red blood cell counts (b), and blood hemoglobin levels (c) were measured before disease induction (day 0, open bars), and after treatment with an irrelevant control Ab (closed bars) or an anti-MIF Ab (hatched bars) over days 7 to 21 . Data are shown as the mean \pm SEM for six animals. ${ }^{*} p<$ 0.05 , and NS, not significant by ANOVA.

\section{Blood Cell Counts}

Immunization of rats with rabbit IgG caused a significant increase in the white blood cell (wbc) count ( $15.2 \pm 3.8 \mathrm{vs} .7 .8 \pm 2.3 \times 10^{6} \mathrm{wbc} / \mathrm{ml}$ in normal rats, $p<0.05)$. White blood cell counts remained elevated in both the anti-MIF- and control Ab-treated rats over the 2l-day study (Fig. 3a). Severe anemia was evident in control Ab-treated animals on day 21 , with a significant reduction in red blood cell counts and blood hemoglobin levels. In contrast, animals treated with the anti-MIF Ab prevented the development of anemia (Fig. 3b, c).

\section{Renal Leukocytic Infiltration}

Compared with normal rats, there was a 10 -fold increase in glomerular leukocytes and a 5-fold
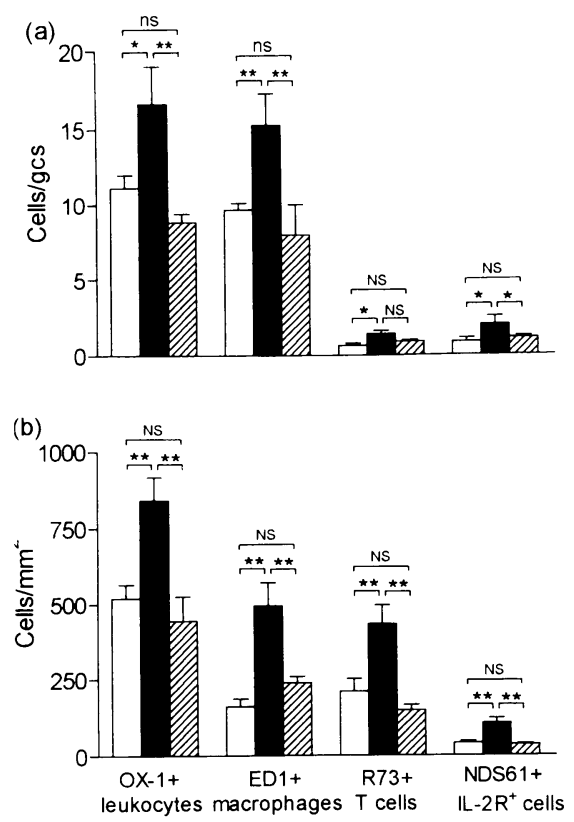

Fig. 4. Anti-MIF Ab treatment halts renal leukocyte infiltration in rat anti-GBM disease. The number of leukocytes per glomerular cross section (gcs) (a) or per $\mathrm{mm}^{2}$ of the cortical interstitium (b) was scored in animals killed on day 7 of disease without treatment (open bars) and after treatment with an irrelevant control Ab (closed bars) or an anti-MIF Ab (hatched bars) over days 7 to 21 . Data are shown as the mean \pm SEM for six animals. ${ }^{*} p<$ $0.05,{ }^{* *} p<0.01$, and NS, not significant by ANOVA.

increase in interstitial leukocytes on day 7 of anti-GBM disease $(p<0.01)$. Macrophages were the main infiltrating cell type in the glomerulus, while a mixed macrophage and $\mathrm{T}$ cell infiltrate was seen in the interstitium (Fig. 4). A further increase in macrophage and $\mathrm{T}$ cell infiltration, including $\mathrm{T}$ cell activation (interleukin-2 receptor expression), was seen in those animals treated with the control Ab over days 7 to 21 . This increase in leukocyte infiltration and activation was abrogated by anti-MIF Ab treatment (Fig. 4).

\section{Renal Production of MIF and IL-I}

Constitutive MIF mRNA and protein expression is evident in some glomerular and tubular epithelial cells in normal rat kidney (Figs. 5A and 6). Both the number of MIF positive cells and the intensity of staining was increased in glomeruli and tubules on day 7 of untreated disease (Figs. 5B and 6). A further increase in renal MIF expression was evident in those animals treated with the control Ab over days 7 to 21 (Figs. 5C 

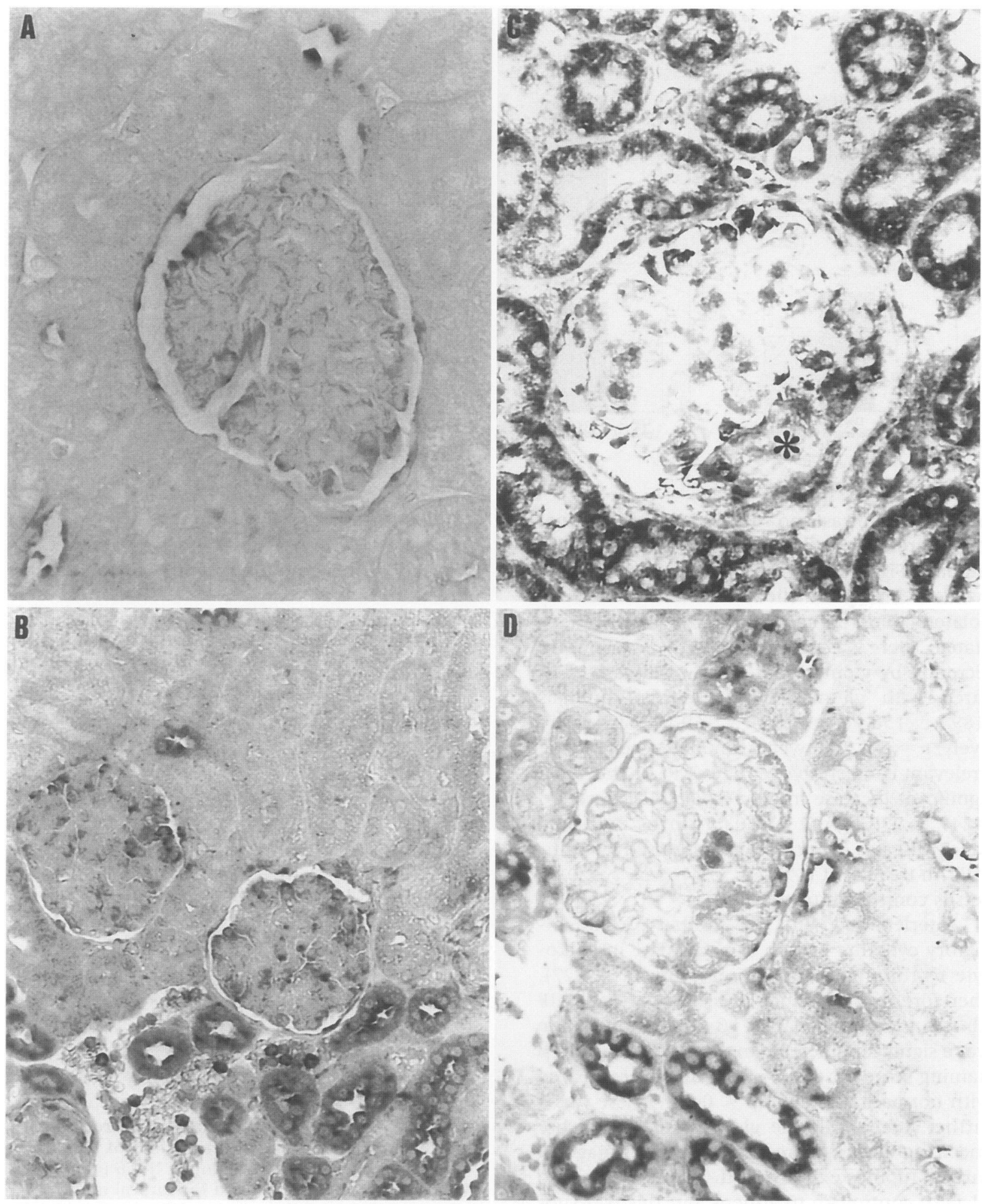

Fig. 5. In situ hybridization of MIF mRNA expression in tissue sections of normal and diseased kidney. (A) Normal rat kidney showing constitutive MIF mRNA expression by a few podocytes in the glomerulus and some tubular epithelial cells. (B) Up-regulation of MIF mRNA on day 7 of untreated rat anti-GBM disease. Note the increase in the number of glomerular MIF mRNA ${ }^{+}$cells and in the focal pattern of increased tubular MIF expression. (C) Further up-regulation of glomerular and

tubular MIF mRNA expression is seen on day 21 of anti-GBM disease treated with the control Ab. Note the expression of MIF mRNA in a glomerular crescent (asterix). (D) Reduction in glomerular and tubular MIF mRNA expression on day 21 of anti-GBM disease following treatment with the anti-MIF $\mathrm{Ab}$ compared with control Ab shown in (C). Sections were counterstained with PAS minus hematoxylin. Magnification, $\times 250$. 

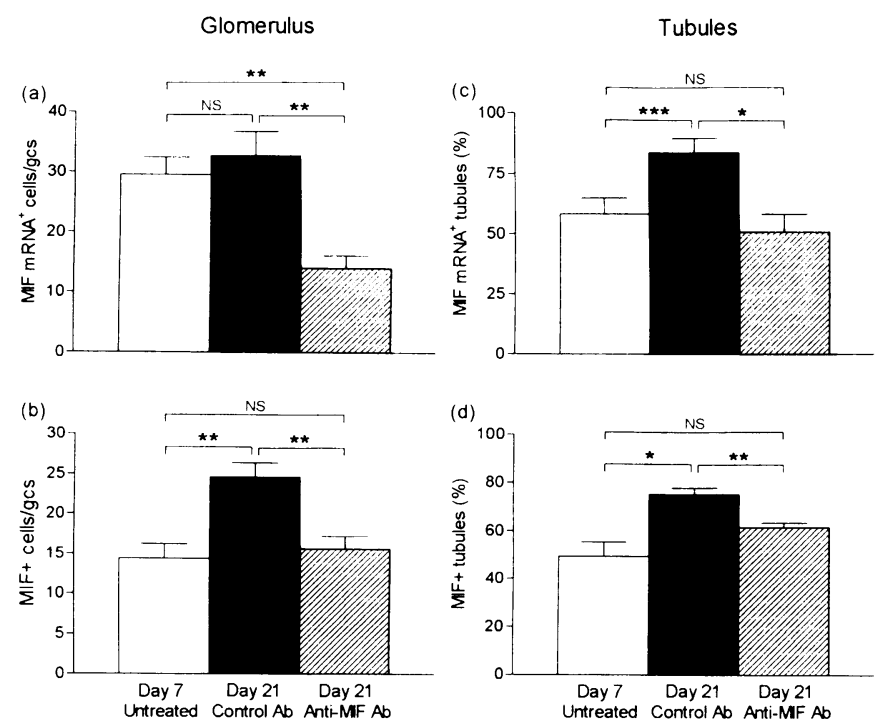

Fig. 6. Anti-MIF Ab treatment suppresses renal MIF production in rat anti-GBM disease. Quantitation of in situ hybridization and immunohistochemistry staining of tissue sections was used to determine the number of glomerular cells $(a, b)$ and tubules (c, d) expressing MIF mRNA $(a, c)$ and MIF protein (b, d) in animals killed on day 7 of disease without treatment (open bars), and after treatment with an irrelevant control $\mathrm{Ab}$ (closed bars) or an anti-MIF $\mathrm{Ab}$ (hatched bars) over days 7 to 21 . Data are shown as the mean \pm SEM for six animals. ${ }^{*} p<0.05$, ${ }^{* *} p<0.01, * * * p<0.001$, and NS, not significant by ANOVA. Values for normal rats are $6.5 \pm 1$ MIF mRNA $^{+}$cells/gcs; $0.8 \pm 0.2$ MIF protein $^{+}$ cells/gcs; $29 \pm 2.5 \%$ MIF mRNA ${ }^{+}$tubules, and $23 \pm 2.5$ MIF protein ${ }^{+}$tubules (all $p<0.01$ versus day 7 untreated).

and 6 ). In contrast, no further increase in renal MIF expression was seen in anti-MIF Ab-treated animals (Figs. 5D and 6). As a second method to evaluate MIF production, secretion of MIF by isolated glomeruli cultured for $24 \mathrm{hr}$ was quantitated. There was no increase in the level of MIF secretion by glomeruli at day 7 of disease compared with glomeruli from normal animals (1894 \pm 150 versus $1955 \pm 169 \mathrm{pg} / \mathrm{ml}$, respectively, $p=$ N.S.). However, animals receiving the irrelevant control Ab over days 7 to 21 showed a significant increase in glomerular MIF secretion (4249 $\pm 977 \mathrm{pg} / \mathrm{ml}, p<0.05$ versus untreated day 7 disease), which was suppressed by antiMIF Ab treatment $(1571 \pm 177 \mathrm{pg} / \mathrm{ml}, p<0.05$ versus control $\mathrm{Ab}$ treated).

Interleukin-l (IL-l) is another pro-inflammatory cytokine known to participate in leukocyte recruitment in this disease model $(22,27)$. Therefore, we examined the effect of anti-MIF $\mathrm{Ab}$ treatment on renal $\mathrm{IL}-1 \beta$ production. There was a significant increase in the glomerular IL- $1 \beta$ staining score on day 7 of the disease compared with normal rat kidney $(p<0.05)$. There was a further increase in the glomerular IL-l $\beta$ score and a significant increase in the percentage of cortical tubules expressing IL- $\beta$ over days 7 to 21 with control Ab treatment, but this was suppressed by anti-MIF Ab treatment (Fig. 7).

\section{Cellular and Humoral Antigen Responses}

Since MIF has previously been shown to play an important role in both the skin delayed-type hypersensitivity (DTH) response and the primary antibody response in vivo $(4,5)$, we examined the effect of anti-MIF Ab treatment on these aspects of the immune response in this disease
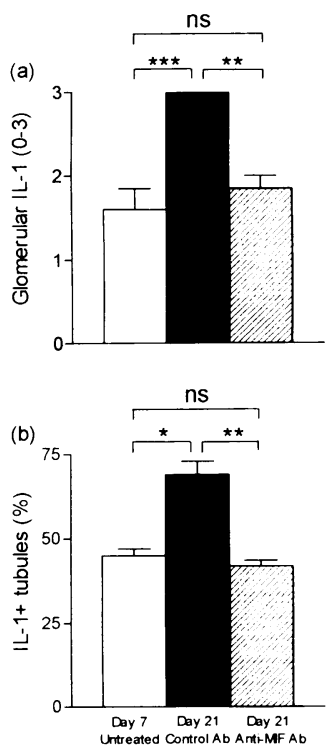

Fig. 7. Anti-MIF Ab treatment suppresses renal IL-1 $\beta$ production in rat anti-GBM disease. Immunohistochemistry staining of IL- $1 \beta$ protein was assessed in (a) glomeruli and (b) cortical tubules. Data are shown as the mean \pm SEM for six animals killed on day 7 of disease without treatment (open bars), and after treatment with an irrelevant control $\mathrm{Ab}$ (closed bars) or an anti-MIF Ab (hatched bars) over days 7 to $21 .{ }^{*} p<0.05,{ }^{* *} p<0.01,{ }^{* *} p<$ 0.001 , and NS, not significant by ANOVA. Values for normal rats are $0.8 \pm 0.1$ glomerular IL- $1 \beta^{+}$score $(p<0.001$ versus day 7 untreated) and $53 \pm 7 \%$ IL- $1 \beta^{+}$tubules ( $p=$ N.S. versus day 7 untreated). 


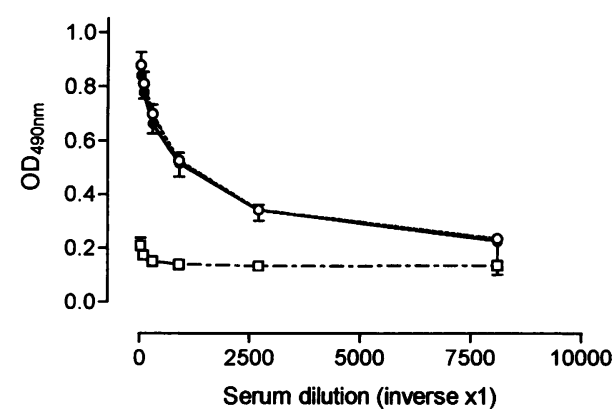

Fig. 8. Anti-MIF Ab treatment does not affect the humoral immune response in rat anti-GBM disease. Serum levels of rat antibodies against the immunizing antigen (rabbit IgG) were determined by ELISA in diseased animals treated with the control Ab (closed circles, solid line) or anti-MIF Ab (open circles, dotted line). Serum from normal, nonimmunized rats (open squares, dashed line), shows the assay background. Data are shown as the mean \pm SEM for six animals.

model. Animals treated with the control $\mathrm{Ab}$ mounted a vigorous skin response to the immunizing antigen (rabbit IgG), but not to an irrelevant antigen (horse IgG) $(3.25 \pm 0.23$ versus $2.13 \pm 0.17 \mathrm{~mm}$, respectively; $p<0.001$ ) or to PBS. There was a lesser degree of skin swelling in response to challenge with rabbit IgG compared with the irrelevant antigen in animals treated with the anti-MIF $\mathrm{Ab}(2.68 \pm 0.08$ versus $2.23 \pm$ 0.1 , respectively; $p<0.001$ ), which represents a $60 \%$ reduction in the antigen-specific skin response compared with control Ab-treated animals $(p<0.001)$. In contrast, there was no dif-

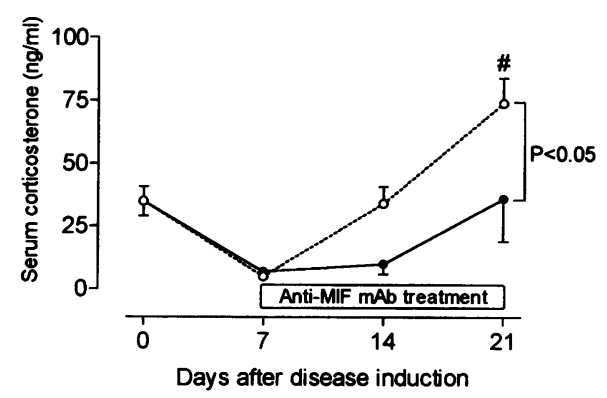

Fig. 9. Anti-MIF Ab treatment increases serum corticosterone levels in rat anti-GBM disease. Serum corticosterone levels were measured using a radioimmunoassay in rats receiving control $\mathrm{Ab}$ (closed circles, solid line) or anti-MIF Ab (open circles, dotted line) treatment over days 7 to 21 . Normal rat serum corticosterone levels (day 0 ) are shown. Data are shown as the mean \pm SEM for six animals. ${ }^{*} p<0.05$ versus day 7 by ANOVA.
Table 1. Serum corticosterone levels correlate with disease parameters in rat anti-GBM disease

\begin{tabular}{|c|c|}
\hline $\begin{array}{l}\text { Disease Parameter } \\
\text { Measured on Day } 21^{a}\end{array}$ & $\begin{array}{c}\text { Day } 21 \text { Serum } \\
\text { Corticosterone } \\
\text { Level }^{a}\end{array}$ \\
\hline Glomerular MIF mRNA ${ }^{+}$cells & $r=-0.77, p=0.005$ \\
\hline Tubular MIF mRNA ${ }^{+}$cells & $r=-0.87, p<0.001$ \\
\hline Glomerular EDl $^{+}$macrophage & $r=-0.57, p=$ N.S. \\
\hline Interstitial $\mathrm{EDI}^{+}$macrophages & $r=-0.57, p<0.001$ \\
\hline Interstitial IL- $2 \mathrm{R}^{+}$cells & $r=-0.82, p=0.002$ \\
\hline Proteinuria & $r=-0.61, p=0.046$ \\
\hline Serum creatinine & $r=-0.82, p=0.002$ \\
\hline Creatinine clearance & $r=0.72, p=0.013$ \\
\hline Serum urea & $r=-0.72, p=0.013$ \\
\hline
\end{tabular}

${ }^{a}$ Data are pooled from both control and anti-MIF Abtreated animals on day $21(n=12)$ and analyzed using the Pearson single correlation coefficient.

ference in the titer of circulating rat antibodies against the immunizing antigen between the two treatment groups (Fig. 8). Similarly, no differences between the two Ab treatment groups were evident in glomerular deposition of rabbit IgG, rat IgG, or C3 as assessed by semi-quantitative immunofluorescence staining (data not shown).

\section{Endogenous Corticosterone Levels}

Serum samples were taken between 9 and 10 a.m. from anesthetised animals to minimize variation in corticosterone levels. Compared with serum corticosterone levels in normal rats $(35.6 \pm 5.8 \mathrm{pg} / \mathrm{ml})$, there was a significant fall in corticosterone levels on day 7 of rat anti-GBM disease ( $p<0.01$ vs. normal) (Fig. 9). Animals receiving control $\mathrm{Ab}$ treatment showed a rebound with serum corticosterone returning to normal levels by day 21 of the disease. However, animals treated with anti-MIF Ab showed a more rapid and significantly greater rebound in endogenous serum corticosterone levels compared with control Ab-treated animals (Fig. 9). Indeed, corticosterone levels in animals treated with the anti-MIF Ab were significantly elevated above normal levels by day $21(p<0.05)$.

To analyze the relationship between corticosterone levels and disease, we compared the 
plasma corticosterone levels in all animals on day $21(n=12)$ with various disease parameters using the Pearson single correlation coefficient (Table 1). The number of glomerular and tubular cells expressing MIF mRNA gave a highly significant negative correlation with corticosterone levels. The number of interstitial macrophages and immune-activated cells $\left(\mathrm{IL}-2 \mathrm{R}^{+}\right)$, but not glomerular macrophage infiltration, gave a negative correlation with corticosterone levels. In addition, parameters of renal injury and renal function gave a significant negative correlation with corticosterone levels (Table 1).

\section{Discussion}

While a variety of intervention strategies have been shown to be successful in preventing the induction of the immune response that leads to the development of immune-mediated diseases, it has proven far more difficult to halt or even partially reverse progressive tissue injury once it is established. Indeed, this is the crucial test of any new therapeutic strategy, as patients invariably present to the clinician after their disease is already established. The present study has, therefore, extended previous results by demonstrating that antibody-based neutralization of MIF activity can halt and even partially reverse established crescentic glomerulonephritis in the rat.

The ability of anti-MIF Ab treatment to inhibit established disease can be attributed to two distinct mechanisms. First, MIF is known to participate directly in the cellular immune response $(4,5)$. Consistent with a previous study $(12)$, the cellular immune response in this disease was suppressed by anti-MIF Ab treatment as demonstrated by inhibition of the skin DTH response, a reduced macrophage and $\mathrm{T}$ cell infiltrate within the kidney, and a reduction in immune activation (IL-2R expression) of the mononuclear cell infiltrate. The inhibition of leukocyte infiltration may be due in part to inhibition of local IL-1 $\beta$ production since this cytokine is known to promote renal leukocyte accumulation through induction of molecules such as intercellular adhesion molecule- 1 and monocyte chemoattractant protein-1 (27-29). In contrast to the cellular immune response, anti-MIF Ab treatment had no effect upon the secondary antibody response.

The second mechanism by which neutralization of MIF activity suppressed this disease is through counter-regulation of glucocorticoid production. Whereas administration of recombi- nant MIF has been shown to inhibit dexamethasone mediated suppression of lethal endotoxaemia in mice (6), the relationship between endogenous production of MIF and glucocorticoids in immune-mediated disease is unknown. There is an increase in both circulating MIF levels and local renal MIF production during the development of rat anti-GBM disease $(10,11)$. The current study showed that increased MIF production during the early phase of disease development was associated with a suppression of serum corticosterone levels. In addition, neutralization of MIF activity caused an increase in corticosterone levels to above that seen in normal animals. These findings suggest that endogenous MIF may act to regulate glucocorticoid levels in immune-mediated glomerulonephritis. Furthermore, the increase in corticosterone levels seen with anti-MIF Ab treatment may have contributed to the suppression of the cellular immune response. Indeed, a sharp rise in endogenous glucocorticoid levels has been shown to play a crucial role in the resolution of acute paralyzing injury in rat experimental allergic encephalomyelitis (EAE) (30). Also, the basal level of endogenous serum corticosterone has been shown to be an important factor in the susceptibility of Lewis, but not PVG.RTl ${ }^{\mathrm{C}}$, rats to the induction of EAE (31). The finding that serum corticosterone did not rise above normal levels in control $\mathrm{Ab}-$ treated anti-GBM disease probably reflects the very aggressive nature of this disease model, which progresses rapidly towards end-stage renal failure.

Erythropoietin is produced by interstitial cells within the kidney $(32,33)$. Anemia is a common complication of renal failure caused by a reduction in erythropoietin production in the injured renal interstitium (34). In the current study, anti-MIF Ab treatment of established antiGBM disease prevented the development of severe anemia, demonstrating that neutralizing MIF activity provides substantial protection against interstitial injury during disease progression.

In summary, this study has demonstrated that blocking MIF activity can partially reverse established crescentic glomerulonephritis. While MIF has been identified previously to act as a counter-regulator of glucocorticoid action (6), the present data suggest that in vivo MIF may also influence glucocorticoid levels, providing an additional level of regulation on the ensuing inflammatory and immune responses. 


\section{Acknowledgments}

This study was supported by grants from the National Health and Medical Research Council of Australia (no. 9960106) and the National Institutes of Health (no. 13591). We are grateful to Ms. M. Lo for corticosterone assay.

\section{References}

1. David JR. (1966) Delayed hypersensitivity in vitro: its mediation by cell-free substances formed by lymphoid cell-antigen interaction. Proc. Natl. Acad. Sci. U.S.A. 56: 72-77.

2. Bloom BR, Bennett B. (1966) Mechanism of a reaction in vitro associated with delayed-type hypersensitivity. Science 153: 80-82.

3. Calandra T, Bucala R. (1997) Macrophage migration inhibitory factor (MIF): a glucocorticoid counter-regulator within the immune system. Crit. Rev. Immunol. 17: 77-88.

4. Bernhagen J, Bacher M, Calandra T, et al. (1996) An essential role for macrophage migration inhibitory factor in the tuberculin delayed-type hypersensitivity reaction. J. Exp. Med. 183: 277-282.

5. Bacher M, Metz CN, Calandra T, et al. (1996) An essential regulatory role for macrophage migration inhibitory factor in T-cell activation. Proc. Natl. Acad. Sci. U.S.A. 93: 7849-7854.

6. Calandra T, Bernhagen J, Metz CN, et al. (1995) MIF as a glucocorticoid-induced modulator of cytokine production. Nature 376: 68-71.

7. Nishno T, Bernhagen J, Shijki H, Calandra T, Dohl K, Bucala R. (1995) Localization of macrophage migration inhibitory factor (MIF) to secretory granules within the corticotrophic and thyrotrophic cells of the pituitary gland. Mol. Med. 1: 781788.

8. Bacher M, Meinhardt A, Lan HY, et al. (1997) Migration inhibitory factor expression in experimentally induced endotoxemia. Am. J. Pathol. 150: 235-246.

9. Calandra T, Bernhagen J, Mitchell RA, Bucala R. (1994) The macrophage is an important and previously unrecognized source of macrophage migration inhibitory factor. J. Exp. Med. 179: 18951902.

10. Lan HY, Mu W, Yang N, et al. (1996) De novo renal expression of macrophage migration inhibitory factor (MIF) during the development of rat crescentic glomerulonephritis. Am. J. Pathol. 149: 1119-1127.

11. Lan HY, Yang N, Metz C, et al. (1997) TNF-alpha up-regulates renal MIF expression in rat crescentic glomerulonephritis. Mol. Med. 3: 136-144.

12. Lan HY, Bacher M, Yang N, et al. (1997) The pathogenic role of macrophage migration inhibitory factor in immunologically induced kidney disease in the rat. J. Exp. Med. 185: 1455-1465.
13. Bernhagen J, Calandra $\mathrm{T}$, Mitchell RA, et al. (1993) MIF is a pituitary-derived cytokine that potentiates lethal endotoxaemia. Nature 365: 756-759.

14. Sunderland CA, McMaster WR, Williams AF. (1979) Purification with monoclonal antibody of a predominant leukocyte-common antigen and glycoprotein from rat thymocytes. Eur. J. Immunol. 9: 155-159.

15. Dijkstra CD, Dopp EA, Joling P, Kraal G. (1985) The heterogeneity of mononuclear phagocytes in lymphoid organs: distinct macrophage subpopulations in the rat recognized by monoclonal antibodies ED1, ED2 and ED3. Immunology 54: 589-599.

16. Damoiseaux JG, Dopp EA, Calame W, Chao D, MacPherson GG, Dijkstra CD. (1994) Rat macrophage lysosomal membrane antigen recognized by monoclonal antibody ED1. Immunology 83: $140-147$.

17. Hunig T, Wallny HJ, Hartley JK, Lawetzky A, Tiefenthaler G. (1989) A monoclonal antibody to a constant determinant of the rat $\mathrm{T}$ cell antigen receptor that induces $T$ cell activation. Differential reactivity with subsets of immature and mature $\mathrm{T}$ lymphocytes. J. Exp. Med. 169: 73-86.

18. Tellides G, Dallman MJ, Morris PJ. (1989) Mechanism of action of interleukin-2 receptor (IL-2R) monoclonal antibody (MAb) therapy: target cell depletion or inhibition of function?. Transplant. Proc. 21: 997-998.

19. Schotanus K, Holtkamp GM, Meloen RH, et al. (1995) Domains of rat interleukin I beta involved in type I receptor binding. Endocrinology 136: 332339.

20. Mitchell R, Bacher M, Bernhagen J, Pushkarskaya T, Seldin MF, Bucala R. (1995) Cloning and characterization of the gene for mouse macrophage migration inhibitory factor (MIF). J. Immunol. 154: 3863-3870.

21. Lan HY, Paterson DJ, Atkins RC. (1991) Initiation and evolution of interstitial leukocytic infiltration in experimental glomerulonephritis. Kidney Int. 40: $425-433$.

22. Lan HY, Nikolic-Paterson DJ, Zarama M, Vannice JL, Atkins RC. (1993) Suppression of experimental crescentic glomerulonephritis by the interleukin-1 receptor antagonist. Kidney Int. 43: 479-485.

23. Lan HY, Nikolic-Paterson DJ, Mu W, Atkins RC. (1995) Local macrophage proliferation in the progression of glomerular and tubulointerstitial injury in rat anti-GBM glomerulonephritis. Kidney Int. 48: 753-760.

24. Lan HY, Zarama M, Nikolic-Paterson DJ, Kerr PG, Atkins RC. (1993) Suppression of experimental crescentic glomerulonephritis by deoxyspergualin. J. Am. Soc. Nephrol. 3: 1765-1774.

25. Lan HY, Mu W, Ng Y-Y, Nikolic-Paterson DJ, Atkins RC. (1996) A simple, reliable, and sensitive method of nonradioactive in situ hybridization: use of microwave heating to improve hybridiza- 
tion efficiency and preserve tissue morphology. J. Histochem. Cytochem. 44: 281-287.

26. Yu XQ, Nikolic-Paterson DJ, W. Mu, et al. (1998) A functional role for osteopontin in experimental crescentic glomerulonephritis in the rat. Proc. Assoc. Am. Physicians 110: 50-64.

27. Nikolic-Paterson DJ, Lan HY, Hill PA, Vannice JL, Atkins RC. (1994) Suppression of experimental glomerulonephritis by the interleukin-1 receptor antagonist: inhibition of intercellular adhesion molecule-1 expression. J. Am. Soc. Nephrol. 4: 1695-1700.

28. Tang WW, Feng L, Vannice JL, Wilson CB. (1994) Interleukin-1 receptor antagonist ameliorates experimental anti-glomerular basement membrane antibody-associated glomerulonephritis. J. Clin. Invest. 93: 273-279.

29. Tang WW, Qi M, Warren JS. (1996) Monocyte chemoattractant protein 1 mediates glomerular macrophage infiltration in anti-GBM Ab GN. Kidney Int. 50: 665-671.

30. MacPhee IA, Antoni FA, Mason DW. (1989) Spontaneous recovery of rats from experimental allergic encephalomyelitis is dependent on regulation of the immune system by endogenous adrenal corticosteroids. J. Exp. Med. 169: 431445.

31. Mason DW, MacPhee IA, Antoni FA. (1990) The role of the neuroendocrine system in determining genetic susceptibility to experimental allergic encephalomyelitis in the rat. Immunology 70: $1-5$.

32. Lacombe C, Da SJ, Bruneval P, et al. (1988) Peritubular cells are the site of erythropoietin synthesis in the murine hypoxic kidney. J. Clin. Invest. 81: $620-623$.

33. Maxwell PH, Ferguson DP, Nicholls LG, Johnson MH, Ratcliffe PJ. (1997) The interstitial response to renal injury-fibroblast-like cells show phenotypic changes and have reduced potential for erythropoietin gene expression. Kidney Int. 52: 715-724.

34. Eschbach JW. (1989) The anemia of chronic renal failure: pathophysiology and the effects of recombinant erythropoietin. Kidney Int. 35: 134-148. 